\title{
Weight and Fuel saving Potential Through Changed Cabin and Fuselage Design
}

\author{
Jörg Fuchte* and Björn Nagel ${ }^{\dagger}$ and Volker Gollnick ${ }^{\ddagger}$ \\ German Aerospace Center, Air Transportation Systems, 21079 Hamburg, Germany
}

\begin{abstract}
This paper investigates the potential of changed cabin and fuselage design for improved aircraft performance. The cabin of current short and medium range aircraft offers potential for weight saving through application of new technology and leaner layout. The paper investigates aircraft in the size of current single aisle aircraft. New airlines business models and changed customer priorities motivate to re-evaluate the design decisions of current aircraft. The overall effect on aircraft's performance is not known to public domain research and is challenging to assess with conceptual design methods. This paper fills this void by introducing potential changes and estimates their potential. Fuel savings of up to $9 \%$ are possible if the aircraft is reduced to its primary purpose. The effect of introducing new technology offers only marginal improvements. Most effect is gained by downsizing the fuselage and reducing passenger amenities in re-designed aircraft. If such changes ever find their way into future aircraft cabins depends on the priorities set by airlines and ultimately by the passengers.
\end{abstract}

\section{Introduction}

\section{A. Motivation}

Aircraft technology has reached a level of high sophistication. Yet, the challenge of diminishing supplies of fossil fuels and hence a steep increase of energy costs motivates the exploitation of even small efficiency reserves. The proposed technologies are addressing different technology fields. An overview can by found in paper by Jupp, ${ }^{1}$ which lists a number of possible technologies for future aircraft. In aerodynamics the application of laminar flow is supposed to yield substantial advantages. At the same time the challenges of that technology are substantial. Operational factors reduce the usability of laminar flow, as described by Wicke $^{2}$ in an extensive analysis. Wicke identifies fuel savings between 0 and $8 \%$ depending on mission range. Another suggestion is the usage of very large aspect ratio wings, as described by the Boeing in its contribution to the Sustainable Ultra-Green Aircraft Research. ${ }^{3}$ Also small potentials have been investigated, like the application of electric taxi motors for more efficient airport operations. Dzikus ${ }^{4}$ identifies saving potential of up to $3 \%$ depending on the airports used and mission distances flown. Changed requirements for future aircraft may also yield advantages, like a reduction of the aircraft design range. Mane ${ }^{5}$ identifies the potential of $8 \%$ when design range is limited to $1000 \mathrm{~nm}$. All technologies improve the aircraft's performance, but most come either with operational drawbacks or are limited in application and reduce the operational flexibility of the airline.

Little attention has been devoted in public domain research to a change in the general layout of the aircraft cabin. Current aircraft are usually taken as pattern. However, current aircraft have been designed in the 1980ies and 1990ies with focus on network carriers. Business models in the short range sector have changed since. The market has partly been taken by low cost carriers. Network carriers have adapted many features of the low cost carriers to compete. They have streamlined their cabin offerings. Changing passenger priorities are key to this development. For short range connections, many passengers prioritize affordability

*Research Engineer, Integrated Aircraft Design, Blohmstrasse 18, and AIAA Member Grade.

${ }^{\dagger}$ Head of Department, Integrated Aircraft Design, Blohmstrasse 18, and AIAA Member Grade.

${ }^{\ddagger}$ Head of Institute, Integrated Aircraft Design, Blohmstrasse 18, and AIAA Member Grade. 
and flight schedule over comfort.

Progress in material technology allows the usage of lighter materials in the aircraft cabin. Although cabin interiors have been optimized for low weight for a long time, there are always evolutionary reductions in specific weight. German cabin technology specialist Diehl Aircabin ${ }^{6}$ mentions some potential. Leaner cabin seating options are on offer for current single aisles., ${ }^{78}$ Different to most initially mentioned technologies cabin technology can often be introduced to in-service aircraft. Cabins have to be replaced every 5 to 10 years depending on the number of cycles. The inclusion of newest technology has a beneficial effect on aircraft performance, albeit possibly only a small one.

Today's single aisle aircraft with more than 120 seats are exclusively build by Airbus and Boeing and remarkably similar in their layout and performance. However, many capabilities of these aircraft remain unused by the airlines. These capabilities include parts of the service modules and a large proportion of the cargo hold. High density layouts can be ordered. However, the maximum number of passengers is often not limited by physical space but by the emergency evacuation requirements.

The actual comfort of the passenger may appear strongly affected by this. However, studies have shown that the physical space is only one aspect of the perceived comfort. Many more aspects are taken into account, including those not related to the aircraft at all (like boarding procedures or security checks)., ${ }^{910}$

\section{B. Research Objective}

The objective of this paper is the analysis of efficiency potentials in the field of fuselage and cabin design. For that purpose the cabin is changed down to the minimum standards required for passenger transport. The technologies introduced are by no means revolutionary. Actually, most changes proposed in this paper could be implemented today. If such changes are actually adopted depends on the priorities set by the airlines and the passengers.

For the investigation a tool chain for cabin and fuselage design is introduced. The chain allows a very detailed weight estimation of the fuselage including the cabin. This design environment is connected to a conceptual aircraft design tool named VAMPzero. ${ }^{11}$ The changes are translated into fuel and weight savings. While the fuel savings have an obvious advantage, weight saving translates into lower charges, and possible savings in procurement cost.

Savings coming from lower complexity or lower maintenance cost are not considered. It is assumed that these savings are small enough to be neglected in comparison to fuel cost, crew cost and aircraft finance.

\section{Cabin and Fuselage Weights in Aircraft Design}

This section explains the basic motivation for cabin weight saving and and shows the contribution of the cabin weights to the overall empty weight of current aircraft.

\section{A. Fuselage Effect on Aircraft Performance}

Fuel efficiency of an aircraft can be measured in terms of specific range. That is the range an aircraft can accomplish with a given amount of fuel. For unaccelerated level cruise flight the specific range can be calculated like shon in equation 1.

The SFC represents the specific fuel consumption of the engine per delivered unit of thrust during one hour. The lift-over-drag ratio includes both the zero-lift drag caused by friction and interference as well as lift induced drag. It is obvious that the increase in either of the factors of the numerator or decrease in either of the factors of the denominator enhances the performance of the aircraft. The fuselage has a direct 
influence on the weight and the drag.

$$
S R=\frac{V_{\text {ground }} \cdot \frac{L}{D}}{S F C \cdot W}
$$

\begin{tabular}{|c|c|c|c|}
\hline \multirow{5}{*}{ with: } & $S R:$ & Specific Range & $\frac{n m}{k g}$ \\
\hline & $V_{\text {ground }}$ : & Speed over Ground & {$\left[\frac{n m}{h}\right]$} \\
\hline & $\frac{L}{D}:$ & Lift over Drag ratio & {$[-]$} \\
\hline & $W:$ & Aircraft Weight & {$[\mathrm{kg}]$} \\
\hline & $S F C$ : & Specific Fuel Consumption & $\frac{\mathrm{kg} \cdot \mathrm{h}}{\mathrm{daN}}$ \\
\hline
\end{tabular}

The fuselage represents a major proportion of the aircraft's weight. A weight breakdown is shown in figure 1. It is taken from Boeing's SUGAR presentation ${ }^{3}$ in the context of the Subsonic Ultra Green Aircraft Research (SUGAR). The breakdown presents the fuselage structure at $10 \%$ of the take-off weight. Furnishings and Operational Items add another 10\%. If both weights are seen in relation to the aircraft's empty weight, the fuselage structures make up 18\% and the furnishings and equipment another $17 \%$ of the operating empty weight.

The weight of the fuselage is connected directly to the layout requirements of the cabin. The fuselage length has to be sufficient for the number of passengers. Besides the passenger seating additional space is required for exits, service installations and the flight deck. Tapering of the front and rear fuselage further increases the

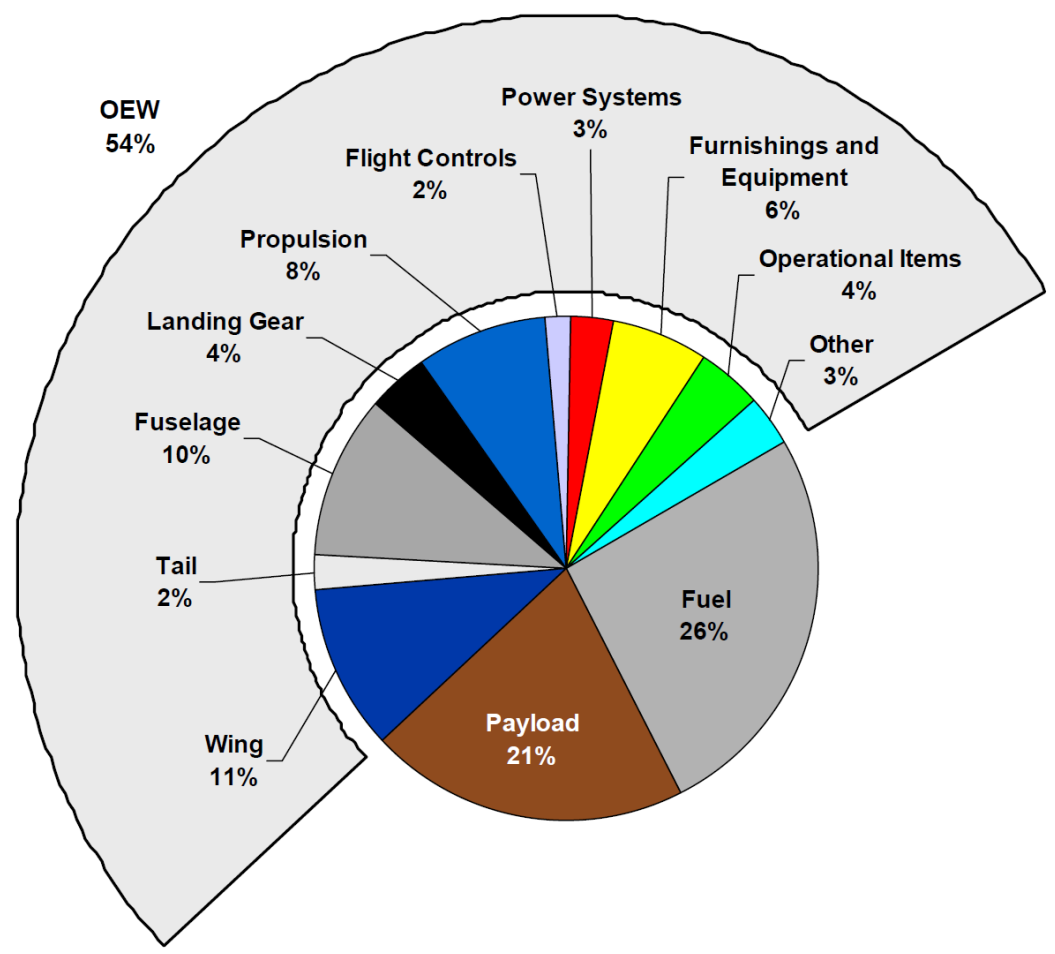
length.

Many systems are installed in the fuselage. Not all are directly linked to the fuselage layout. Systems that grow with the fuselage are the environmental control system and parts of both the electrical and the hydraulic distribution.

The fuselage further contributes to the aircraft's drag. The drag can be categorized into zero-lift drag, lift-induced drag, trim drag and wave drag. The fuselage directly contributes to the zero-lift drag as shown in figure 2. Indirectly the fuselage contributes to the trim drag by providing the lever arm of the horizontal tail. The zero-lift drag is proportional to the surface of the fuselage, hence a reduced fuselage size directly reduces the aircraft's drag. The design of the fuselage nose and tail has a strong influence on the zero-lift drag. The correct tapering of the rear fuselage reduces adverse pressure drag. The fuselage determines the effective lever arm of the tail surfaces, and hence has a direct influence on trim drag and size of the tail surfaces. 


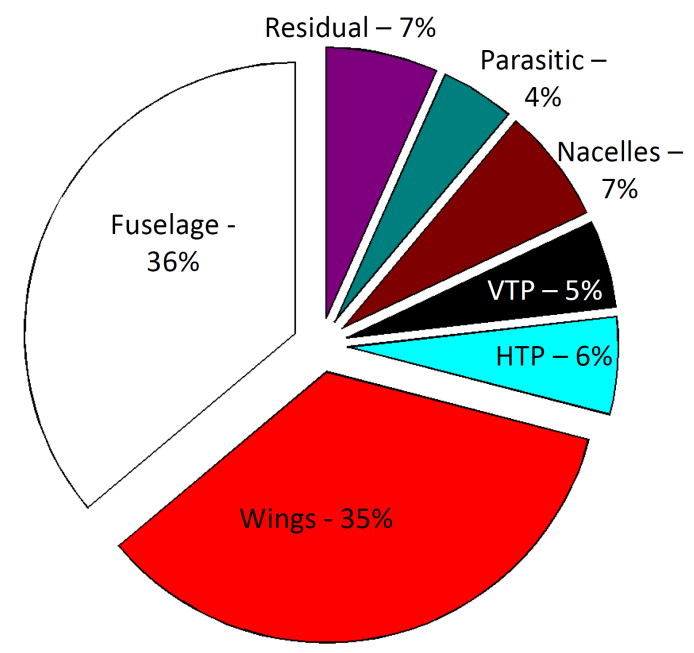

Figure 2. Drag breakdown of a typical single aisle medium range aircraft. Own analysis.

and cabin design are shown. Even within these system inconsitencies exist, for example in the distinction between cargo lining and cargo loading system. These inconsistencies are caused by items that serve mutliple purposes or - in the example of the cargo loading system - are actually lining but need to be stronger if a cargo loading system is installed. The numbering system originally extends from the ATA chapter numbering system for aircraft systems, but has no connection to it any more.

\begin{tabular}{|c|l|c|l|}
\hline \multicolumn{2}{|c|}{ Furnishings } & \multicolumn{2}{|c|}{ Operational Items } \\
\hline Nmb & Group Name & Nmb & Group Name \\
\hline $50-0$ & Insulation & $60-1$ & Documents and Tool Kit \\
$50-1$ & Trim Panels & $60-2$ & Galley Structure \\
$50-2$ & Crew Seats & $60-3$ & Passenger Seats \\
$50-3$ & Partitions Stowages, Doors & $60-6$ & Inflight Entertainment \\
$50-4$ & Toilets & $61-0$ & Emergency Equipment \\
$50-5$ & Overhead Bins & $61-1$ & Water for Galleys \& Lav \\
$50-6$ & Floor Covering & $61-4$ & Catering \\
$50-7$ & Cargo Linings & $61-5$ & Crew \\
$50-8$ & Cargo Loading System & & \\
51 & Emergency Oxygen & & \\
52 & Lighting & & \\
53 & Water \& Waste Installation & & \\
\hline
\end{tabular}

Table 1. Mass accounting system used at Airbus. ${ }^{13}$ The numbers were originally oriented on ATA chapter system for systems, but have no direct relationship to it any more.

Detailed weight breakdowns of the cabin masses are difficult to come by. Commonly used aircraft design textbooks cite total furnishing weight without offering a more detailed breakdown. Through a SAWE publication by Anderson the breakdown of the B757-200 is known. ${ }^{14}$ In the configuration with 186 seats in 2 classes, the furnishings and operational item weigh 6235kg. According to Boeing's Aircraft Characteristics manual ${ }^{15}$ the empty weight of the B757-200 is $58.3 \mathrm{t}$. The resulting $11 \%$ fraction differs from above numbers of the more recent SUGAR report. An older analysis by Beltramo ${ }^{16}$ gives the amount of furnishing and equipment as $13.3 \%$ to $14.5 \%$ of manufacturer's empty weight .

The data of Beltramo is based on aircraft available in the early 1970ies. The detailed breakdowns are 
shown in table 2. The different weight accounting does not allow a comparison, nor to speak of an estimation how new technologies can actually reduce the weight of the cabin interior. The Douglas values (left side) represent the average of three different aircraft, characterized small, medium and widebody.

\begin{tabular}{|c|c|c|c|}
\hline \multicolumn{2}{|c|}{ Beltramo (Douglas) ${ }^{16}$} & \multicolumn{2}{|l|}{ Anderson (Boeing) $)^{14}$} \\
\hline Weight Group & Distribution [\%] & Weight Group & Distribution $[\%]$ \\
\hline Lavatory & 4.3 & Lining \& Lighting & 11.4 \\
\hline Fresh Water System & 1.3 & Insulation & 6.1 \\
\hline Cargo Handling & 2.0 & Stowage, Partitions, Seats, Carpet & 48.2 \\
\hline Galley Structure \& Equipment & 11.0 & Water \& Waste System, Lavatories & 9.4 \\
\hline Floor Covering & 3.7 & Galleys & 5.6 \\
\hline Insulation & 10.7 & Emergency Equipment, Oygen & 6.9 \\
\hline Flight Deck Interior & 1.3 & Cargo Compartment & 12.4 \\
\hline Emergency Oxygen & 2.7 & & \\
\hline Interior (incl. Bins) & 26.7 & & \\
\hline Passenger Seats & 34.7 & & \\
\hline Crew Seats & 2.3 & & \\
\hline
\end{tabular}

Table 2. Furnishing and Equipment breakdown from different sources. The numbers are relative to the total furnishings and operational items weight.

\section{Weight Saving Potential}

The cabin interior adds a considerable amount of weight to the aircraft and hence many efforts aim at reducing this weight. Today's cabin interiors are already light-weight. Further weight can be shed if the higher cost or lower life-time are accepted. Benefits are usually more incremental.

Some potential exists in the cabin monuments. The first option is classic weight saving through optimized layout of galley structures. Plaumann ${ }^{17}$ describes how new lightweight galley structures are tested for their dynamic behavior. Additionally, solutions exist for low-weight galley equipment and trolleys. However, galleys remain heavy equipment. A true weight saving can be achieved if no galley is installed at all. Same applies for the lavatory, while a minimum number has to be provided. Solutions exist to use the available space with higher efficiency. Schliwa ${ }^{18}$ of Airbus introduced a new option for current Airbus single aisles.

Seats represent a substantial part of the furnishing and equipment, roughly 30 to $40 \%$ of the entire weight (see table 2). New materials and new priorities for economy class seating have allowed considerable weight saving. Examplary models are offered by Recaro ${ }^{7}$ and Pitch Aircraft Seating. ${ }^{8}$ However, this is usually connected to a loss in comfort. In business and first class the individual seat weight is actually growing, owed to the many comfort features today standard for such a seat .

Some areas in the cabin are actually growing in weight. Individual inflight entertainment systems are standard on long range aircraft. The screens, power supplies and data center easily amount to more than half a ton on a long range widebody. Overhead bins are designed larger today to accommodate more carry-on luggage. Overhead bins are of considerable weight as they have to withstand high vertical accelerations in case of a crash.

Overall, weight saving of current equipment will have a very modest influence on future cabins. With some chance any weight saving will be compensated by new requirements regarding equipment. Further, interiors are build for durability and have to withstand 5 to 10 years of service, equaling up to 15000 flight cycles in a short range jet. If reliability is compromised the weight saving does not pay off in monetary terms.

One option of extracting additional efficiency from the cabin is by downsizing it to the actual needs of the passengers and adapting it to current airline business models. This includes the reduction of the number of service modules and the deletion of cargo holds. If seating standards are reduced and the fuselage is optimized, more weight saving is possible as the fuselage becomes shorter. 


\section{Methodology}

The methods used for analysis are extended conceptual aircraft design methods. Conceptual aircraft design denotes the initial phase of aircraft design when only limited amount of information on the design is available. The methods used for aerodynamic analysis and estimation are based on statistics or simplified physical relationships.

Opposed to classic conceptual aircraft design more focus is put on the fuselage and cabin design. The focus areas of the introduced methodology are:

1. Cabin general layout and cross section design

2. Weight estimation of furnishings and cabin items

3. Fuselage structural weight estimation

\section{A. Cabin Layout}

Cabin design is usually performed using specialized CAD-tools like Pacelab Cabin. ${ }^{19}$ These tools are intended for airline selection processes and much too complex for conceptual aircraft design. Tools for automated cabin layout can vary in complexity. Simple single aisle cabin layouts can be created easily. Estimation formulas allow to derive a cabin and fuselage length from a required number of passengers. This is often achieved by assuming specific floor areas. If more complexity is required a more elaborate tool is needed that tests different monument locations and adheres to rules concerning exit clearances, aisle width and minimum head clearance. In figure 3 the layout of an unusual configuration is shown to demonstrate the tool's ability. The shown layout is not particularly efficient. The shown 150-seat twin aisle has a short constant section and large proportions are in the non-constant section. The tool used in this investigation uses a large number of knowledge based design rules for the creation of the cabin seat plan.

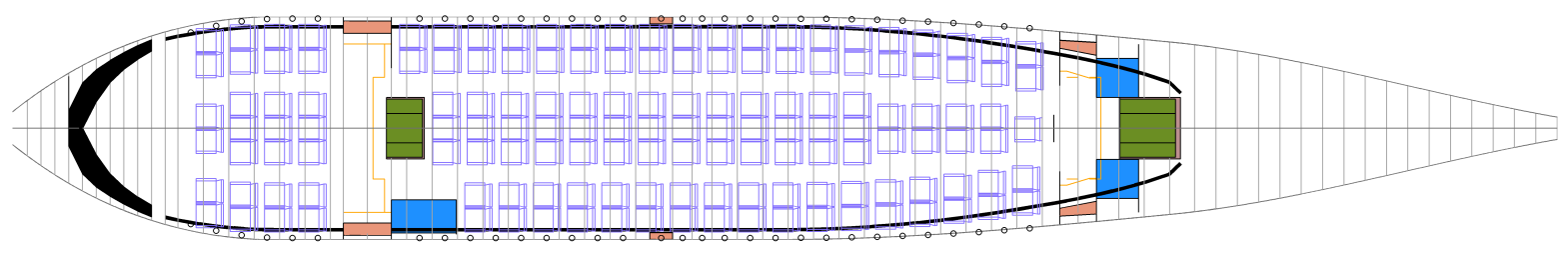

Figure 3. Layout of Passenger Accommodation (LOPA) of a 150-seat twin aisle.

The weight estimation requires a very detailed knowledge of the cabin geometry. Self-evidient the number of seats, monument locations and sizes (in case of galleys and stowages) have to be known. More advanced geometry models are necessary to assess lining surface and overhead bin size. In the lower deck compartment the surface of all lining elements are estimated. The length of the lower deck compartment orients on the fuselage structure and the position of major system components.

In figure 4 an example can be seen that demonstrates the detail level of the cabin layout. The left plot shows how the overhead bins and lining are adapted to the available fuselage volume. Human engineering aspects are considered in the contour calculation. The right plot illustrates position of seats and monuments. The lower deck cargo compartment is also visible.

\section{B. Cabin Weight Estimation}

The cabin weight estimation in preliminary aircraft design is usually based on global geometric parameters. These are for example the fuselage surface, length and width, or the cabin length and diameter. Torenbeek ${ }^{20}$ uses geometric parameters to describe most furnishings. Some systems are described using the number of 


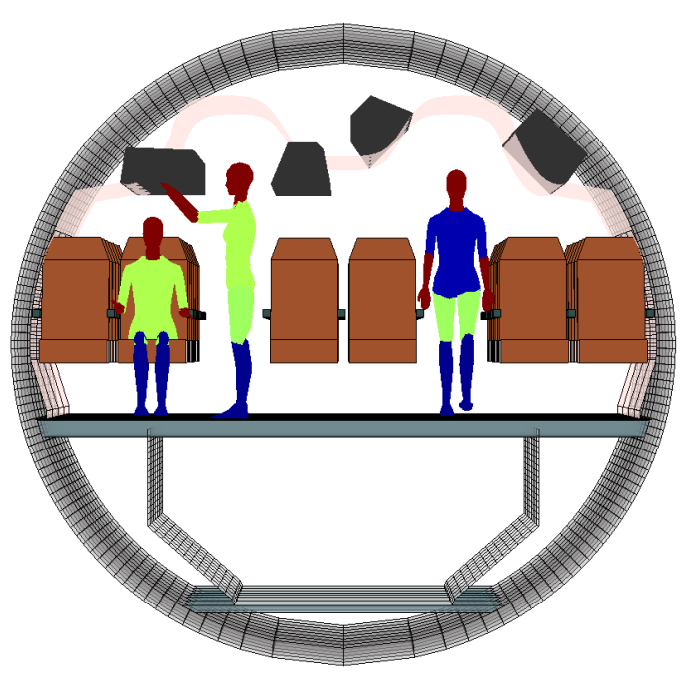

(a) Front View

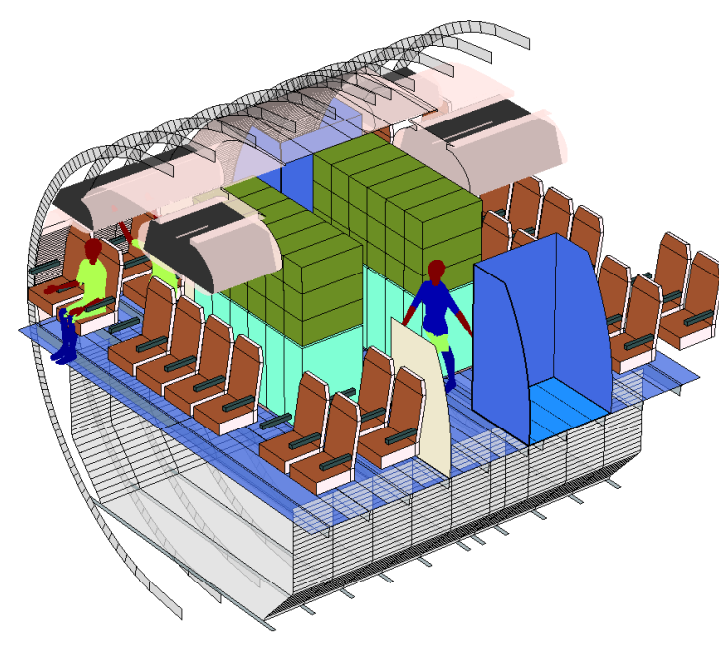

(b) Monuments

Figure 4. 3D view of cross section with overhead bins, seats and monuments. Note that left cross section has pivoting overhead bins.

passengers or discrete values (Torenbeek, ${ }^{20}$ page 291). Raymer ${ }^{21}$ uses a formula based on number of passengers, cargo weight and fuselage surface. Latest statistical formulas introduced by Dorbath ${ }^{22}$ are based solely on fuselage geometry. All approaches produce a reasonable match with current in-service aircraft. All these methods have in common that changes in the cabin are not considered and that it is difficult to asses the effect of innovations for different weight groups. As previously shown, the cabin weights include such diverse elements like monuments structure and cargo loading system.

The introduced weight estimation method was developed with actual aircraft data. The data allowed the identification of component weights in different sections. The necessary geometrical information was created using the previously described cabin and fuselage design process. Data was available for a single aisle and a twin aisle. The major challenge was the identification of parameters that determine the weight of a component. For example, in case of cargo lining the weight of panels does not linearly increase with surface. The actual cargo capacity does matter, too, and if the cargo hold is configured for bulk cargo or containerized cargo. In the passenger cabin the surface areas usually suffice as parameter. Differences exist as larger areas require more sophisticated layout for pressure equalization in case of rapid decompression. Additional component data is taken from an LTH report by Schneider. ${ }^{23}$

Operational items are estimated using the discrete number of passenger seats and actual items. Emergency equipment is oriented on the number of exits. Seats, monuments and lavatory weights are simply summed up. Information on their actual weight can be found in textbooks. However, this information is usually outdated. Finding newer information is a challenge. Sources include proprietary cabin configuration guides and information obtained through direct contacts.

For validation and comparison purposes an aircraft comparable to the B757-200 from the SAWE report ${ }^{14}$ is modeled. The validation is complicated by the fact that the grouping of weight items appears random in the report. As shown in table 2, seats are for example grouped with carpets and stowages. In table 3 the weight breakdown of the cabin shown in figure 5 is provided. The results are very difficult to compare to the report due to the different accounting, and the method cannot be validated against those. The method is validated against the original data. Matching both the single aisle and the twin aisle represents a challenge due to differences in cabin design. Due to the proprietary nature of the original data, the comparison cannot be disclosed like in table 3 . The methods does match weights estimated by the common statistical formulas. 
This, however, is no particularly useful validation as mismatches for different components could compensate each other.

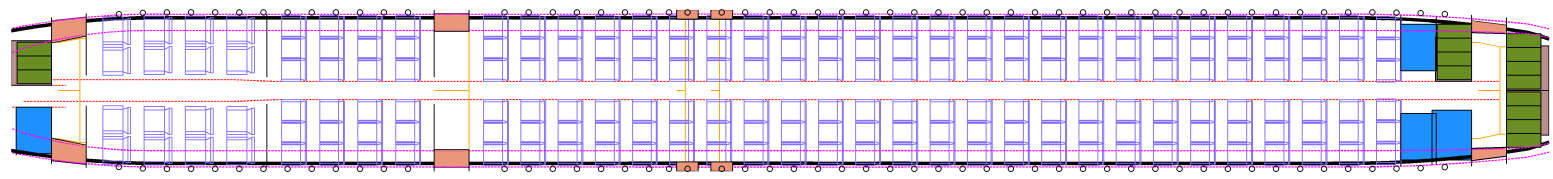

Figure 5. Layout of Passenger Accommodation (LOPA) used for furnishings and operational items weight calculation.

\begin{tabular}{|c|c|c||c|c|c|}
\hline \multicolumn{2}{|c|}{ Furnishings } & \multicolumn{3}{c|}{ Operational Items } \\
\hline $\mathrm{Nmb}$ & Group Name & $\%$ & $\mathrm{Nmb}$ & Group Name & $\%$ \\
\hline $50-0$ & Insulation & 9.0 & $60-1$ & Documents and Tool Kit & 0.6 \\
$50-1$ & Trim Panels & 21.6 & $60-2$ & Galley Structure & 17.8 \\
$50-2$ & Crew Seats & 5.0 & $60-3$ & Passenger Seats & 45.1 \\
$50-3$ & Partitions Stowages, Doors & 2.5 & $60-6$ & Inflight Entertainment & 8 \\
$50-4$ & Toilets & 12.0 & $61-0$ & Emergency Equipment & 8.1 \\
$50-5$ & Overhead Bins & 16.1 & $61-4$ & Catering & 8.5 \\
$50-6$ & Floor Covering & 5.4 & $61-5$ & Crew & 11.9 \\
$50-7$ & Cargo Linings & 10.7 & & & \\
$50-8$ & Cargo Loading System & 0.0 & & & \\
51 & Emergency Oxygen & 3.9 & & & \\
52 & Lighting & 7.6 & & Sum Operational Items & \\
53 & Water \& Waste Installation & 6.2 & &
\end{tabular}

Table 3. Weight breakdown using Airbus-style weight accounting. Numbers are relative to the overall furnishings and operational items weight.

\section{Fuselage Weight Estimation}

Fuselage structural weight estimation offers a number of challenges. The load cases that define the fuselage structure are very diverse, ranging from static maneuver load cases to taxi on uneven surfaces, ${ }^{24} .{ }^{25}$ Pressurization introduces loads that affect fatigue behavior (crack propagation). The fuselage weight is primarily made up of the pressure vessel, the so called shell weight. However, depending on specific design between $30 \%$ and $45 \%$ of the weight are made up of special structures such as bulkheads, center fuselage structure, doors, windows, belly fairing supprot and other. Different weight accounting systems include different items into the fuselage group, making comparisons of values found in literature tricky.

Traditionally fuselage weight is estimated using statistical formulas. These formulas are developed from existing designs. Parameters are identified that influence the weight, and regression allows to calculate the fuselage weight with a number of parameters. Often used parameters are the fuselage surface, length to width ratio, differential pressure. Discrete factors correct for body landing gear or other specific layouts. Often used formulas are that of Torenbeek ${ }^{20}$ Howe $^{26}$ and Raymer. ${ }^{21}$ A recent method published via the $\mathrm{LTH}^{\mathrm{a} 22}$ only uses geometrical factors and achieves a very good match with current generation aircraft.

For a more detailed estimation of the fuselage structural weight more advanced methods with physical relationships are desirable. A number of them have been developed that primarily aim at determining the shell weight using beam theory. Simpson published a method in $1973 .{ }^{27}$ Torenbeek extends this method in his book. ${ }^{20}$ Ardema developed his own method using a similar approach. ${ }^{28}$ An integrated approach is used

\footnotetext{
${ }^{\text {a}}$ LTH stands for "Luftfahrttechnisches Handbuch" (Aerospace Technology Manual) and collects methods for aircraft design.
} 
by Airbus, but remains company confidential. ${ }^{29}$

This method uses the work by Ardema as basis. However, the calibration is different as more recent aircraft weights were available. The method is further enhanced by restricting it to the estimation of shell weight, while other items like floor structure, doors and special structures are calculated using a variety of methods inspired by Torenbeek and others. The method is validated against an overview of the A340-300 published via the LTH. ${ }^{30}$ The method also calculates the discrete weight of passenger and cargo doors and adds it to the overall weight.

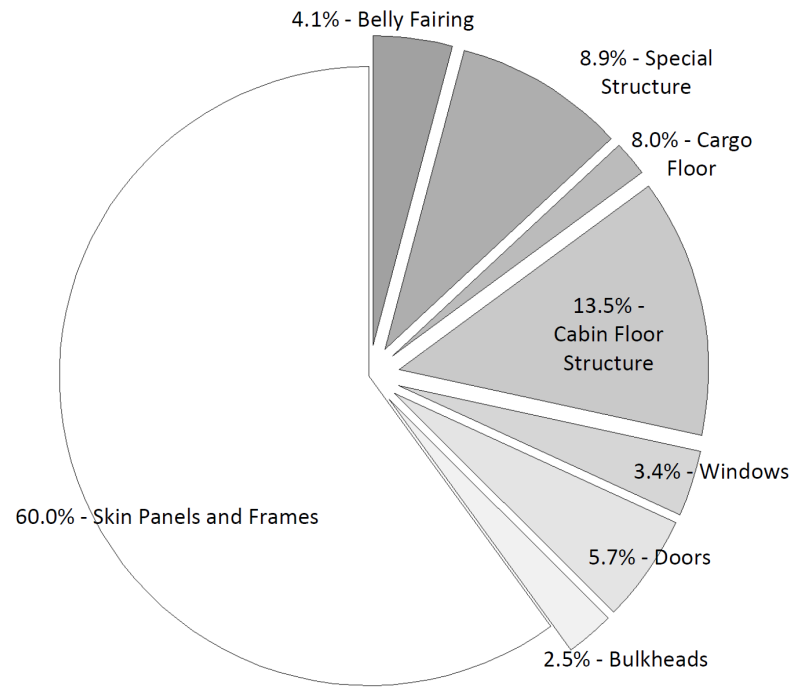

(a) Weight Breakdown

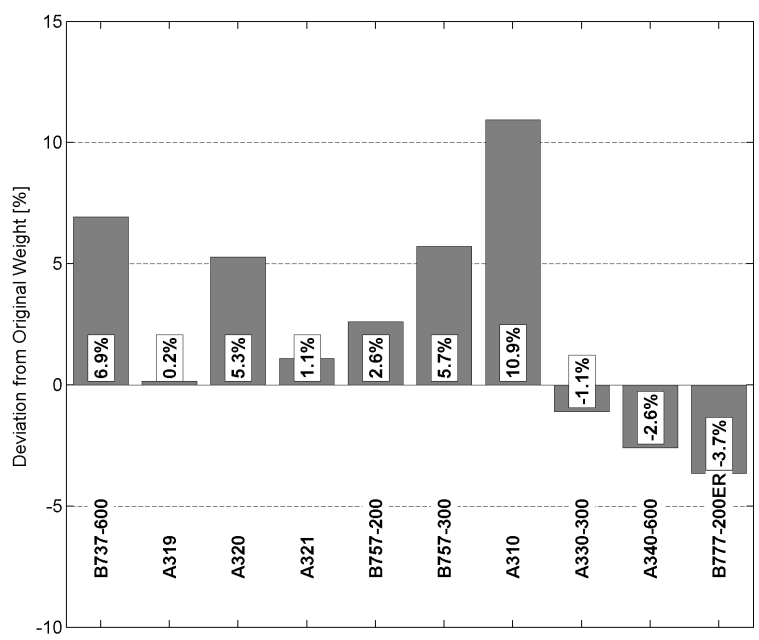

(b) Overall Weight

Figure 6. Weight breakdown of fuselage structural weight. Left hand figure shows a typical breakdown for a single aisle fuselage. Right hand figure shows the deviation from actual fuselage structural weights of existing aircraft.

In figure 6 the weight break down an aircraft comparable to the B757-200 is shown. "Special Structure" includes the nose gear bay, the tail attachments, the keel beam and the wing-fuselage joints. The right hand plot shows how the estimated weight compares to actual weights of existing aircraft. The comparison to actual data is difficult as the individual weight accounting scheme might put some structures (especially the "Special Structures") into different groups. The chosen aircraft feature widely different fuselage layouts, very short single aisles (B737-600) to very long single aisles (B757-300), short and long widebodies. The overall match is acceptable, strong deviations in case of the A310 can be reasoned by its very unusual layout. Compared to other frequently used methods the mean absolute error is reduced to $4 \%$, compared to $6.1 \%$ for the Howe ${ }^{26}$ method and $7.1 \%$ for the $\mathrm{LTH}^{22}$ method.

\section{Assessment Methodology}

For the investigation a number of changes to the cabin are defined. These changes either reduce the weight of the cabin, or allow the reduction of the fuselage size, or both. A number of changes can be applied to aircraft families currently in production. That is, new aircraft could be delivered with these changes. However, detailed design challenges would probably occur and feasibility is not granted. For analysis it is assumed that the aircraft retains the same wing, engine and tails. A fuel burn advantage is then solely caused by less weight.

Another set of configurations would require the re-design of the fuselage. The wing is sized to allow the operation of a 1800nm mission with maximum passenger payload. This is then essentially a new aircraft, albeit with similar configuration and technology assumptions. 


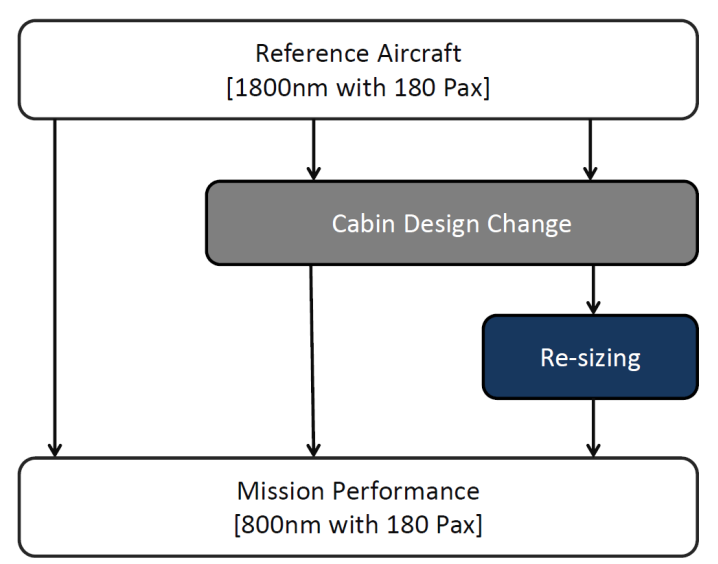

Figure 7. Process Description for Cabin Change Assessment.

cally available.
The fuel burn performance is calculated for a $800 \mathrm{~nm}$ mission with maximum passenger load. The increased range potential is provided for the not redesigned aircraft. Resizing means that wing area and thrust are adapted to the required field performance and design range $(1800 \mathrm{~nm}$ at full passenger load). This sizing process increases the effect of saved weight by incorporating so called snow-ball effects. If surplus floor space exists, the fuselage is shortened.

The sizing is performed using the conceptual design code VAMPzero. ${ }^{31}$ VAMPzero is suitable for such analysis as it allows to set any number of input parameters. In this case, the fuselage properties are directly applied to VAMPzero. Possible interactions such as changed tail size due to shorter tail lever arm are also considered. VAMPzero is in continued developed by the DLR and publi-

The assessment process as shown in figure 7 is supposed to reveal the effects when being retrofitted and when included in new aircraft designs.

\section{Configurations}

This section describes the different configurations. In total ten different cabin-fuselage configurations are used.

\section{Reference Configuration}

The reference configuration is an 180 seat single aisle. The aircraft is equipped with geared turbo-fan engines. The cabin has three lavatories, a small forward galley and a larger rear galley. The seats are 18inch in width and the seat pitch is 31inch. The shown aircraft is very similar to the current A320 but is slightly larger in size. The actual A320 can seat 180 passengers, but only at a seat pitch of 29 inch. The aircraft is equipped with a lower deck cargo hold that uses the majority of unoccupied space in the lower section. The original A320 can accommodate containers when cargo loading system is equipped. However, most airlines do not use this system and rather operate the aircraft with pure bulk. The aircraft has two exits at the front and the back, plus two plug-type emergency exits at each side. The presented configuration is similar to both A320 and B737-800 and represents one of the most efficient configurations. If seat count is increased an additional exit is required.

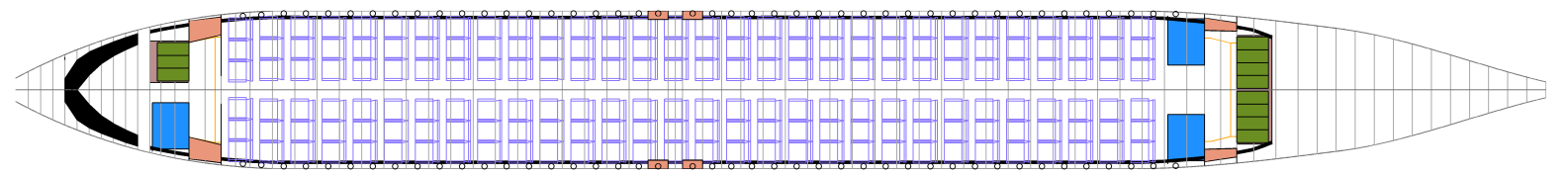

Figure 8. Layout of Passenger Accommodation (LOPA) of the reference aircraft for further comparison.

The aircraft is sized for $1800 \mathrm{~nm}$ with full passenger load. The resulting wing area is $121 \mathrm{sqm}$, the operating empty weight is approximately $42.7 \mathrm{t}$. The wing is slightly smaller than that of either B737-800 or A320 as the effect of the geared turbo-fan is fully considered. Its $15 \%$ better specific fuel consumption allows the reduction of the fuel load and hence a lower weight, resulting in a smaller wing area. 


\section{Configuration 1: New Cabin Interior Technology}

This configuration features exactly the same layout as the reference configuration. The only difference is that specific weights for many components are reduced to account for possible improvements in applied technology. Table 4 shows which weight savings are assumed. These values are loosely confirmed by talks to experts, while exact numbers and the according reference are tightly hold secrets in the industry. It can be said that the assumed technology factors represent the result of a major weight saving effort and are by no means easy to achieve. Possible repercussions such as higher cost or shorter average lifetime are not considered.

\begin{tabular}{|c|cccccc|}
\hline Component & Trim Panels & Overhead Bins & Monuments & Cargo Hold Lining & Seats & Galley Structure \\
\hline Change & $-20 \%$ & $-20 \%$ & $-20 \%$ & $-10 \%$ & $-10 \%$ & $-20 \%$ \\
\hline
\end{tabular}

Table 4. Weight saving through usage of newest material technology and optimized layout.

\section{Configuration 2a \& b: Rear Galley}

The rear galley holds more than $60 \%$ of the total galley volume of the aircraft shown in figure 8 . The number of trays allows a comfortable meal service with drinks. With such services being less often offered on short range routes the rear galley becomes redundant. The small forward galley is in general sufficient for small complementary meal and drink service. The rear galley can be deleted and the space used for the lavatroies, ${ }^{18}$ leaving cabin floor area for additional seats. However, as the reference configuration already operates on the exit capacity limit this would not yield any benefit. The alternative is a shortened fuselage.

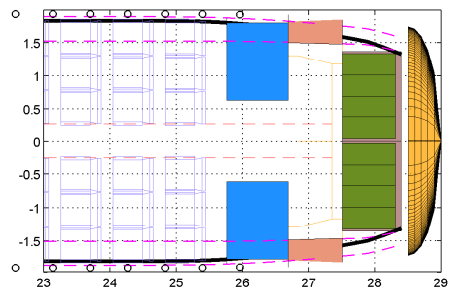

(a) Reference

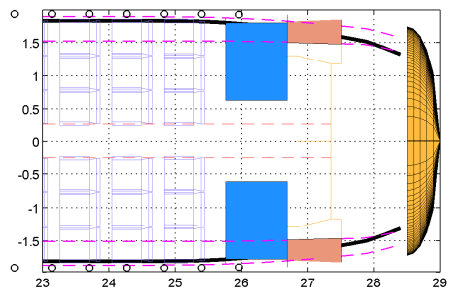

(b) Galley Removed (2a)

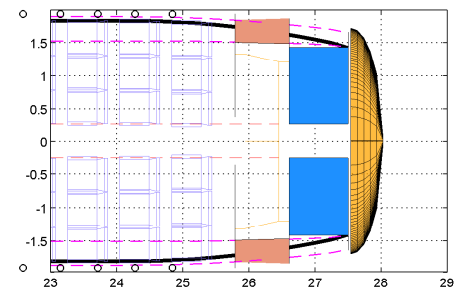

(c) Fuselage Shortened (2b)

Figure 9. Rear cabin as normal layout (left), with removed galley but similar fuselage (middle) and shortened fuselage (left). Note the pressure bulkhead (yellow). The removal of the galley allows a shortening of the fuselage.

\section{Configuration 3: Smaller Cargo Hold}

The cargo hold of current single aisles is primarily used for carriage of passengers baggage. Additional revenue cargo is rarely carried on short domestic missions. A general trend towards less checked luggage is observable. On the other hand, on average more carry-on is carried into the cabin. ${ }^{32}$ As consequence many aircraft fly with virtually empty cargo holds. The cargo hold volume could be reduced in size. Size reduction saves the weight of the cargo hold lining, the floor panels and the cargo door if an entire hold is deleted. The empty space in the fuselage remains unused. Changing the cross section would result in an non-circular cross section which is in effect equally heavy as the circular. A smaller cargo hold can in theory be introduced at existing models, as shown in figure 10. The feasibility of all associated weight savings remains to be confirmed, like removal of the redundant cargo floor beams or all structural strengthening associated with the door. Challenges resulting from different center of gravity are considered manageable. 
The volume of the reduced hold is still 19 cubic meters, in contrast to 54 cubic meters of the original. The volume is sufficient to store more than 180 standard bags.

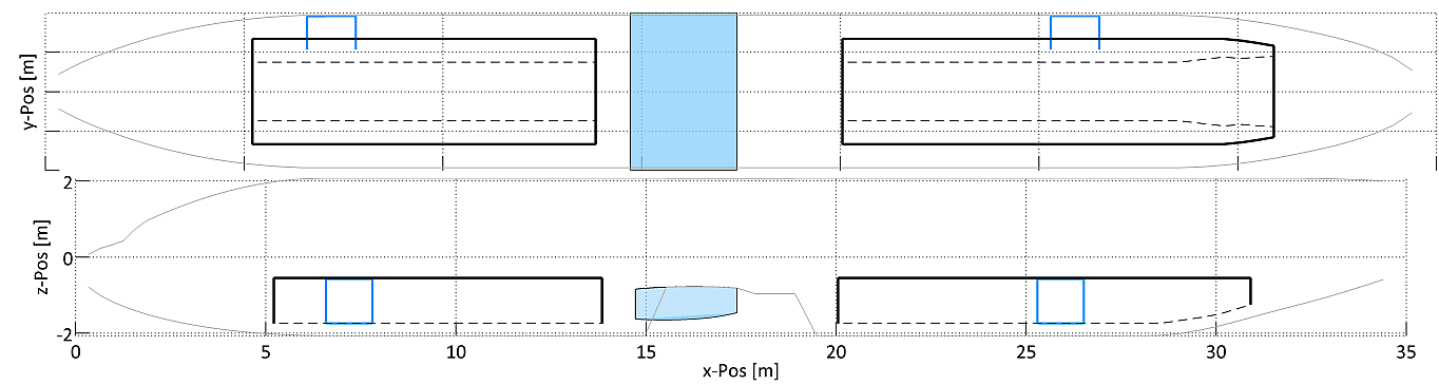

(a) Normal Cargo Hold

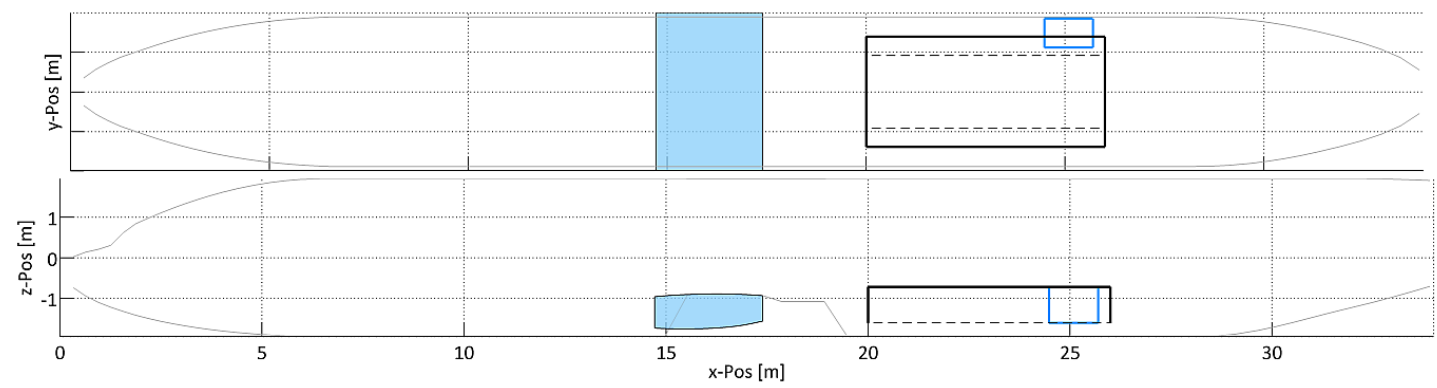

(b) Reduced Cargo Hold

Figure 10. Top and side view of the standard and the reduced cargo hold. The elimination of the entire forward hold also saves the weight and complexity of the forward cargo hold door.

\section{Configuration 4: Combination of all above}

In this configuration all changes that can be applied to existing aircraft are combined. That is, the advanced materials, the deletion of the rear galley (without shortening of the fuselage) and the reduction of the cargo hold. It is assumed that such configuration could be developed from existing aircraft without necessitating change to the basic airframe.

\section{Configuration 5 \& 6 \& 7: Seat Size Reduction}

The A320 allows a seat width of 18 inch. ${ }^{33}$ The B737 cross section restricts the seat width to 17.0-17.5 inch $^{\text {b }}{ }^{34}$ The reference configuration has 18 inch wide seats, which is considered the standard for long range economy seating. However, seat widths of 17 inch are found in many newly delivered cabins. For example, the B777 is operated by many airlines in 10-abreast configuration, resulting in a seat width of 17inch. The B787 in 9-abreast configuration (which is frequently chosen by airlines) results in 17.2 inch seat width. Hence the effect of a seat width reduction to 17inch is studied. No advantage is gained from lighter seats. The advantage is gained through a smaller fuselage. This solution is of course not applicable to existing designs. Configuration 6 uses a smaller seat pitch. The original seat pitch is set at 31inch, which represents the current average in single aisles economy class cabins. The reduction to 29inch reduces this down to a level found in high density seating of the A320 or B737-800. New very slim seats have made this layout more acceptable in terms of passenger comfort, providing more legroom through very slim backrests. However, 29inch can be considered the lower practical limit. The fuselage is shortened and retains the original seat count of 180 seats.

The configuration 7 combines reduced width and reduced pitch, allowing a narrower and shorter fuselage.

\footnotetext{
${ }^{\mathrm{b}}$ The exact limit depends on the chosen aisle width.
} 
Neither of the previous three configurations is retrofitable: the reduced width does not save any weight ${ }^{\mathrm{c}}$. And the seat pitch decrease does not allow more seats as the aircraft is already at its exit capacity limit.

\section{Configuration 8: Combination of all}

The final configuration combines all of the above. It combines smaller cargo hold, a deleted rear galley with shortened fuselage, reduced seat width with lower fuselage diameter and lower pitch with again shortened fuselage.

\section{Summary of Configurations}

In table 5 all investigated configurations are shown. The last column "Retrofit" denotes if the change could be incorporated into new build aircraft of existing models. It does not mean that these changes could be included in in-service aircraft. Fuselage length reduction is achieved by removal of the rear galley and seat pitch reduction. The reduction of length of the reduced seat width configuration is caused by the tail of the aircraft being sized by the average diameter. Hence, a narrower fuselage reduces the required tail cone length.

\begin{tabular}{|c|ccccccc|}
\hline Configuration & Seats & $\begin{array}{c}\text { Seat } \\
\text { Width }\end{array}$ & $\begin{array}{c}\text { Seat } \\
\text { Pitch }\end{array}$ & $\begin{array}{c}\text { Rear } \\
\text { Galley }\end{array}$ & $\begin{array}{c}\text { Fuselage } \\
\text { Length }\end{array}$ & $\begin{array}{c}\text { Cargo } \\
\text { Volume }\end{array}$ & Retrofit \\
\hline Unit & - & inch & inch & & $m$ & $m^{3}$ \\
\hline Reference & 180 & 18 & 31 & YES & 38.73 & 53.87 & - \\
1: Cabin Technology & 180 & 18 & 31 & YES & 38.73 & 53.87 & YES \\
2a: Rear Galley Deletion (no resize) & 180 & 18 & 31 & NO & 38.73 & 53.87 & YES \\
2b: Rear Galley Deletion (resize) & 180 & 18 & 31 & NO & 37.83 & 51.99 & NO \\
3: Minimum Cargo Hold & 180 & 18 & 31 & YES & 38.73 & 18.96 & YES \\
\hline 4a: Combination of \#1, \#2a and \#3 & 180 & 18 & 31 & NO & 38.73 & 18.96 & YES \\
4b: Combination of \#1, \#2b and \#3 & 180 & 18 & 31 & NO & 37.83 & 18.96 & NO \\
\hline 5: Seat Width Reduction & 180 & 17 & 31 & YES & 38.47 & 51.90 & NO \\
6: Seat Pitch Reduction & 180 & 18 & 29 & YES & 37.26 & 52.15 & NO \\
7: Seat Width and Pitch Reduction & 180 & 17 & 29 & YES & 37.00 & 50.09 & NO \\
\hline 8: Combination of \#1, \#2b, \#3 and \#7 & 180 & 17 & 29 & NO & 36.27 & 18.23 & NO \\
\hline
\end{tabular}

Table 5. Summary of configurations. Only some configurations can be installed in (new build) existing aircraft types, the other would require an entirely new fuselage design. The changes in fuselage length for the reduced seat width version originate from a shorter tail section, which is a function of the average diameter.

\section{Results and Analysis}

This section presents the results for the different configurations. As shown in figure 7 only some of the changes are combined with a complete resize (new wings, engines). In table 6 the basic results are shown. That is, the effect on fuselage structural weight, furnishings weight and operational items weight. In order to protect proprietary data, the numbers are given relative to the reference. For better understanding, the fuselage structural weight is about 10t, the furnishings are about $3 \mathrm{t}$ and the operational items sum to roughly $5 \mathrm{t}$.

The structural weight savings in the upper half of the table entries is due to the deletion of the forward cargo door and some cargo floor beams. A real reduction in structural weight is only achieved with a shortened fuselage. Furnishings and operational items shows sometimes significant reduction. The increase in operational items for configuration \#5 and \#6 is due to slightly different rear galley layout. The reduced width configuration has a smaller rear galley, the reduced pitch features a slightly larger one.

${ }^{\mathrm{c}}$ Airbus offers 17 inch seats in the A320 and promises better turnaround time due to the wider aisle. ${ }^{33}$ 


\begin{tabular}{|l|ccc|}
\hline Configuration & $\begin{array}{c}\text { Fuselage } \\
\text { Structural Weight }\end{array}$ & $\begin{array}{c}\text { Furnishing } \\
\text { Weight }\end{array}$ & $\begin{array}{c}\text { Operational } \\
\text { Items Weight }\end{array}$ \\
\hline Reference & 100.0 & 100.0 & 100.0 \\
\hline 1: Cabin Technology & 100.0 & 86.9 & 92.2 \\
2a: Rear Galley Deletion (no resize) & 100.0 & 100.0 & 82.4 \\
2b: Rear Galley Deletion (resize) & 97.8 & 99.9 & 82.3 \\
3: Minimum Cargo Hold & 98.6 & 91.2 & 100.0 \\
\hline 4a: Combination of \#1, \#2a and \#3 & 98.6 & 78.9 & 76.6 \\
4b: Combination of \#1, \#2b and \#3 & 96.8 & 79.1 & 76.6 \\
\hline 5: Seat Width Reduction & 98.6 & 98.2 & 95.7 \\
6: Seat Pitch Reduction & 97.3 & 97.0 & 102.1 \\
7: Seat Width and Pitch Reduction & 95.2 & 95.1 & 100.0 \\
\hline 8: Combination of \#1, \#2b, \#3 and \#7 & 90.7 & 76.0 & 76.5 \\
\hline
\end{tabular}

Table 6. Change of fuselage weights due to changed cabin and fuselage layout. All numbers are relative to the reference configuration.

The initial results include those changes that could be implemented into an existing family. The results are presented in table 7 . The changes result in lower weight, which in turn increases the possible payload. The fuel savings are generated by lower induced drag through reduced average gross weight. Although the changes to the empty weight are remarkable, the resulting change in mission fuel burn are rather poor. The reason is that the combination of high aspect ratio wing and geared turbofan engine makes carriage of additional weight rather efficient. The value for fuel represents the $\mathrm{kg}$ of fuel for $100 \mathrm{~km}$ per passenger. The entire trip fuel difference is shown in the last column.

\begin{tabular}{|l|cccc|cc|c|}
\hline & OEW & MTOW & Pax Fuel & Range & OEW Change & Trip Fuel Change \\
\hline & $\mathrm{kg}$ & $\mathrm{kg}$ & $\mathrm{kg} / 100 \mathrm{~km}$ & $\mathrm{~nm}$ & \%REF & $\%$ REF & $\mathrm{kg}$ \\
\hline Reference & 41682 & 72818 & 2.074 & 1867 & 0 & 0 & 0 \\
1: Cabin Technology & 40895 & 72818 & 2.0732 & 2042 & -1.9 & -0.04 & -2.2 \\
2a: Rear Galley Deletion (no resize) & 40791 & 72818 & 2.073 & 2062 & -2.1 & -0.05 & -2.8 \\
3: Minimum Cargo Hold & 41202 & 72818 & 2.071 & 1977 & -1.2 & -0.14 & -7.7 \\
4a: Combination of \#1, \#2a and \#3 & 39652 & 72818 & 2.068 & 2258 & -4.9 & -0.29 & -16.0 \\
\hline
\end{tabular}

Table 7. Effect of changes that do not necessitate a complete redesign.

The fuel savings are very small and it can be stated with some sureness that no operator would accept such drastic reduction of its aircraft capabilities in expectation of such low advantages. The only real advantage is additional range. However, given the fact that the changes are better suited for short range missions, this is of lesser significance. If the original configuration would allow the installation of additional seats, the result would be more beneficial.

The next table shows the result if a completely new design is targeted. The fuselage can be reduced in size, hence any floor space savings can be translated into a reduced fuselage length. Wing and engines are sized for the design mission, hence snow ball effects add to the saved weight. The fuel savings are substantial and amount to $9 \%$ if all changes are combined. Such aircraft would have significant limitations due to small baggage volume and very small galley volume. It would be limited to short range domestic routes. The reduction in passenger space affects the attractiveness.

In figure 11 the initial reference layout and the final configuration are shown. The only real noticeable change is the cabin length. The reduced cabin width is difficult to depict from the figure.

The results show that the design decisions for the passenger cabin have significant influence on the later 


\begin{tabular}{|l|cccccc|}
\hline Configuration & OEW & MTOW & Pax Fuel & Change OEW & Trip Fuel Saved \\
\hline & $\mathrm{kg}$ & $\mathrm{kg}$ & $\mathrm{kg} / 100 \mathrm{~km}$ & \% REF & \% REF & $\mathrm{kg}$ \\
\hline Reference & 41594 & 72155 & 2.213 & 0 & 0 & -131.6 \\
\hline 1: Cabin Technology & 40719 & 70968 & 2.1625 & -2.1 & -2.3 & -167.8 \\
2b: Rear Galley Deletion (resize) & 40010 & 70265 & 2.1482 & -3.8 & -2.9 & -113.5 \\
3: Minimum Cargo Hold & 40970 & 71391 & 2.1696 & -1.5 & -2.0 & -300.8 \\
\hline 4b: Combination of \#1, \#2b and \#3 & 38771 & 68792 & 2.0938 & -6.8 & -5.4 & -156.4 \\
\hline 5: Seat Width Reduction & 40547 & 70833 & 2.1527 & -2.5 & -2.7 & -140.2 \\
6: Seat Pitch Reduction & 40940 & 71313 & 2.1591 & -1.6 & -2.4 & -182.8 \\
7: Seat Width and Pitch Reduction & 40022 & 70169 & 2.1422 & -3.8 & -3.2 & -1.2 \\
\hline 8: Combination of \#1, \#2b, \#3 and \#7 & 36639 & 66163 & 2.0113 & -11.9 & -9.1 & -488.9 \\
\hline
\end{tabular}

Table 8. Change in weight and trip fuel in case of full resize. All aircraft are sized for 1800nm mission at full passenger load (incl. baggage). The trip fuel is given for a $800 \mathrm{~nm}$ reference mission.

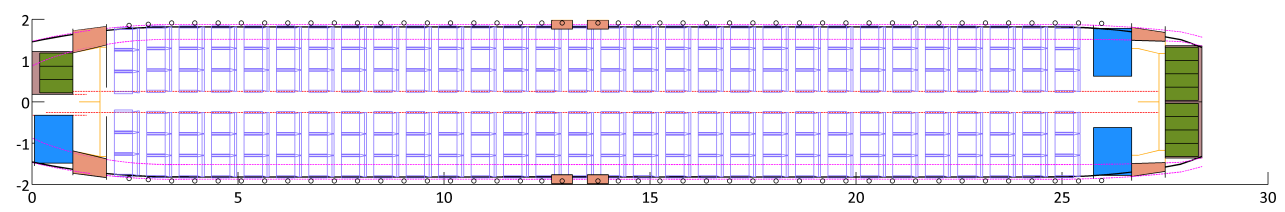

(a) Normal Cargo Hold

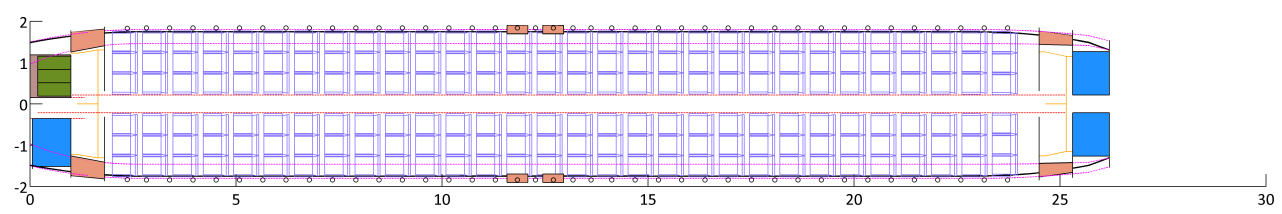

(b) Reduced Cargo Hold

Figure 11. Layout of reference aircraft and configuration 8. The reduction of seat pitch and the deletion of the galley reduces the fuselage length. The reduced width is difficult to identify.

performance. The presented configurations are rather drastic changes that would reduce the attractiveness of the aircraft for many operators. It is primarily attractive for low cost carriers and airlines flying many short domestic routes. However, the intention of the paper is to show that the economic potential is strongly influenced by the cabin design decisions.

\section{Summary and Conclusion}

This paper investigated the effect of changed cabin and fuselage design on aircraft performance. Besides fuel burn the operating empty weight is provided as proxy for resulting direct operating cost. The investigation unveiled that a leaner cabin can reduce aircraft fuel burn by up to $9 \%$ and result in an empty weight reduction of close to $12 \%$. The changes would affect the suitability of the aircraft for many operators and also affect passenger comfort.

However, the introduced changes would probably go unnoticed for many economy class passengers. Meal service on domestic flights is rare. Many passengers renounce the usage of checked luggage due to baggage fees and more convenience at airports. Seat width of 17 inch and seat pitch of 29inch are found in many today's cabin. In fact, a seat width of just more than 17inch is common occurrence in the many of newly delivered widebody aircraft (like B777). 
The proposed changes do not eliminate the option for airlines to install a different seating layout. With exception of the seat width (which is bound to the fuselage diameter) most changes are reversible with loss of passenger seating capacity and additional weight.

Future aircraft should allow an operator to downsize his cabin product to achieve maximum efficiency for his type of operation. Hard limits like emergency exit capacity exist that limit this downsizing today. Passenger comfort may be compromised, but the physical seating space is only one aspect of the perceived comfort by the passenger. It is worthwhile to discuss which comfort level new aircraft shall aim at in presence of increasing fuel prices and maturing technologies. Further, other proposed technologies like high aspect ratio wings or open rotor engines would affect cruising speed, which also represents a disadvantage for the flying customer.

The exact balance depends on the actual market, but aircraft need to allow the maximum usage of the available space. Further, more flexible design should allow a better customization of aircraft with benefit for the aircraft performance. 


\section{References}

${ }^{1}$ J. Jupp, "21st Century Challenges for the Design of Passenger Aircraft," 28th International Congress of the Aeronautical Sciences, 2012.

${ }^{2}$ K. Wicke, M. Kruse, F. Linke, "Mission and Economic Analysis of Aircraft With Natural Laminar Flow," 28th International Congress of the Aeronautical Sciences, 2012.

${ }^{3}$ M. Bradley et al. (Boeing), "Subsonic Ultra Green Aircraft Research - Final Review," Presentation to NASA, 2010.

${ }^{4}$ N. Dzikus, J. Fuchte, "Potential for Fuel Reduction through Electric Taxiing," 11th Aviation Technology, Integration and Operations Conference, 2011.

${ }^{5}$ M. Mane, A. Black, N. Davendralingam, W. A. Crossley, "Exploration of Designing Short-Range High-Capacity Aircraft," 12th Aviation Technology, Integration and Operations Conference, 2012. 2011.

${ }^{6}$ W.-D. Kuhnla, "Innovations and Advanced Technologies for the Future Cabin System," Altair Technology Conference,

${ }^{7}$ RECARO Aircraft Seating, "SL3510 - The slim lightweight seat for short-haul flights," http://www.recaroas.com/sl3510.html, 2013.

${ }^{8}$ Pitch Aircraft Seating, "Introducing the Pitch PF2000," http://www.pitchaircraftseating.co.uk/, 2013.

${ }^{9}$ D. Lee, M. J. Luengo-Prado, "Are passengers willing to pay more for additional legroom," Journal of Air Transport Management, Vol. 10, 2004, pp. 377-383.

${ }^{10} \mathrm{~K}$. Balcombe, I. Fraser, L. Harris, "Consumer willingness to pay for in-flight service and comfort levels: a choice experiment," Journal of Air Transport Management, Vol. 15, 2009, pp. 221-226.

${ }^{11}$ D. Böhnke, B. Nagel, V. Gollnick, "An Approach to Multi-Fidelity in Conceptual Aircraft Design in Distributed Design Environments," IEEE Aerospace Conference, 2011.

${ }^{12}$ M. Nita, D. Scholz, "From Preliminary Aircraft Cabin Design to Cabin Optimization," 59. Deutscher Luft- und Raumfahrtkongress, 2010.

${ }^{13}$ Airbus Engineering - Mass Properties, Airbus Mass Standard Reference Guide - Issue 3, 2008.

${ }^{14}$ R. L. Anderson, "B757 Payloads Weight Optimization," Society of Allied Weight Engineers, , No. SAWE-1571, 1983.

${ }^{15}$ Boeing Commercial Airplanes, Airplane Characteristics For Airport Planning - B757, 2002.

${ }^{16}$ M. Beltramo, D. Trapp, B. Kimoto, D. Marsh, "Parametric Study of Transport Aircraft Systems Cost and Weight," , No. NASA-CR-151970, 1977.

${ }^{17}$ B. Plaumann, O. Rasmussen, R. Seemann, D. Krause, "Dynamic Simulation and Testing for Lighter Cabin Interior," Workshop of Aircraft System Technology, 2013.

${ }^{18}$ R. Schliwa, J. Cremers, "Airbus Space-Flex Development," Workshop of Aircraft System Technology, 2013.

${ }^{19}$ PACE, "Pacelab Cabin 7," www.pace.de/products/cabin-configuration/pacelab-cabin-7.html, 2013.

${ }^{20}$ E. Torenbeek, Synthesis of Subsonic Airplane Design, Delft University Press, 1976.

${ }^{21}$ D. P. Raymer, Aircraft Design - A Conceptual Approach - 2nd Edition, AIAA Education Series, 1992.

${ }^{22}$ F. Dorbath, "Civil Jet Transport Aircraft - Statistical Mass Estimation," Luftfahrttechnisches Handbuch, , No. MA 401 12-01, 2011.

${ }^{23}$ F. Schneider, "Flächenbezogene Masse für Fussbodenplatten," Luftfahrttechnisches Handbuch, , No. MA 508 22-11, 1998.

${ }^{24}$ T. L. Lomax, Structural Loads Analysis for Commercial Transport Aircraft: Theory and Practice, AIAA Education Series, 1996.

${ }^{25}$ M. C.-Y. Niu, Airframe Structural Design, Conmilit Press, 1988.

${ }^{26}$ D. Howe, Aircraft Conceptual Design Synthesis, Professional Engineering Publishing, 2000.

${ }^{27}$ D. M. Simpson, "Fuselage Structure Weight Prediction," Society of Allied Weight Engineers, , No. SAWE-981, 1973.

${ }^{28}$ M. Ardema et al, "Analytical Fuselage and Wing Weight Estimation of Transport Aircraft," Technical Report NASATM-110392, , No. NASA-TM-110392, 1996.

${ }^{29}$ A. Schmidt, M. Läpple, R. Kelm, "Advanced Fuselage Weight Prediction for the New Generation of Transport Aircraft," Society of Allied Weight Engineers, , No. SAWE-2406, 1997.

${ }^{30}$ R. v. Baur, H. Oltmanns, "Entwicklung der Rumpfmasse über die Zeit - A340-300," Luftfahrttechnisches Handbuch, , No. MA 508 12-51, 2003.

${ }^{31}$ D. Böhnke, "VAMPzero - Conceptual Design for the Needs of MDO," http://code.google.com/p/vampzero/, 2012.

${ }^{32}$ Z. Berdowski, F.N. van den Broek-Serie, J.T. Jetten, Y.Kawabata, "Survey on standard weights of passengers and baggage," 2009.

${ }^{33}$ Airbus, "A320 Family Briefing," 2005.

${ }^{34}$ Boeing Commercial Airplanes, "Airplane Characteristics For Airport Planning - B737," 2005. 